\title{
HISTÓRIA, MEMÓRIA E GERAÇÃO: REMISSÃO INICIAL A UMA DISCUSSÃO POLÍTICO-EDUCACIONAL
}

\author{
Lívia Diana Rocha Magalhães ${ }^{1}$
}

\section{RESUMO}

Nesse ensaio, abordamos como os conceitos de geração e de memória podem ser um dos recursos analíticos possíveis para pensarmos a relação entre experiências passadas e a análise das prioridades políticas de uma dada sociedade, dentro do estudo da história da educação, considerando que uma sociedade, ainda que não seja historicamente a mesma dantes, pode operacionalizar o uso e a atualização constante do passado em favor da continuidade de dada condução e construção política, educacional, no presente.

Palavras-chave: Geração; Memória; História; Educação.

\section{HISTORY, MEMORY. AND GENERATION: INITIAL RETURN A DISCUSSION POLITICAL EDUCATION}

\begin{abstract}
:
In this essay, we discuss how the concepts of generation and memory, may be one possible analytical capabilities to think through the relationship between past experiences and examine the political priorities of a given society, within the study of the history of education, whereas a society that historically it is not the same before, can operate using the constant updating of the past in favor of the continuity of driving and given political, educational construction at present.
\end{abstract}

Keywords: Generation. Memory. History. Education.

\section{INTRODUÇÃO}

Nesse ensaio, pretendemos destacar como os conceitos sobre a memória social, coletiva, geracional, podem se constituir em um importante recurso heurístico para se pensar "[...] como a atua a memória coletiva a longo, médio e curto prazo, com relação ao que é consubstancial, quer dizer, com relação à transmissão do conhecido, de sua revisão e atualização constante, de sua reelaboração [...]" (GONZALEZ, 2007, p.8) para a análise das prioridades políticas de uma dada sociedade, dentro do estudo da história da educação.

Estamos, inevitavelmente, nos apropriando desses conceitos para observar que as memórias geracionais coletivas, supostamente, têm funções expressivas nas sociedades sobre as quais estes estão atuando, exercendo a condução política.

Assim, necessariamente, esta preocupação nos remete à pertinência da relação entre presente e passado, em sua consideração diacrônica e sincrônica, em sua manifestação concreta, no processo de definição de políticas, de projetos de educação e de sociedade. 
A cada vez que adentramos pelo campo de estudos da memória, vamos concluindo que ainda é preciso reconstituir as distintas perspectivas das suas questões epistemológicas. Os fundamentos da memória foram se tornando cada vez mais revistos a partir do século $\mathrm{XX}$, e as fronteiras encontradas em outros campos de estudos vão sendo substituídas ou ampliadas sucessivamente, por meio desse campo, dada a sua capacidade de apreender outras questões conceituais, ainda latentes, não vistas ou assumidas por outras áreas do saber.

A abertura para diversos campos do saber e a complexidade resultante desse processo tem nos levado a muitos lugares e alternativas, mas, por outro lado, também nos leva a muitas indagações de ordem epistemológica que estão exigindo nossa atenção.

Há uma instigante discussão sobre a relação entre Memória e História do presente ou, como Aróstegui (2004) denomina, de "história coetânea". Da educação brota uma interpretação que apreende ambas as perspectivas (da História e da psicologia social) para destacar que há uma incidência desses tempos sobre as oportunidades educacionais geracionais e sobre suas memórias. Destarte, quase todas as discussões que relacionam memória e geração remetem principalmente ao conceito de geração desenvolvido por Mannheim (1928) e ao conceito de Memória Coletiva desenvolvido por Halbwachs (1950), autores que se apoiam na relação entre tempo histórico comum e às suas múltiplas temporalidades, e nos remetem à análise sobre as memórias geracionais.

\section{UMA APROXIMAÇÃO DO ESTADO DA ARTE}

Sobretudo no século XX, os conceitos de geração e de memória receberam mais atenção do ponto de vista científico. $O$ fenômeno geracional passou a fazer parte principalmente das preocupações das ciências que tratam do comportamento social, ganhando vigor com as chamadas correntes positivistas que se preocupavam com o tema da sucessão e da "duração ordinária da vida humana" (COMTE apud MARÍAS, 1970, p.30-35). Havia uma preocupação em calcular o período médio de tempo em que uma geração seria substituída, ou seja, como a tradição pode continuar sendo mantida, em face de aspectos passageiros e tempestuosos inerentes principalmente à juventude. Preocupação, sobretudo, com a substituição de valores estabelecidos, com o tempo de duração da vida humana e seus efeitos sobre o progresso, buscando, assim, o entendimento de uma lei humana sobre o desenvolvimento histórico.

Como sabemos, é mais especificadamente no século XIX que a memória adquire o caráter de fenômeno e objeto científico. Maurice Halbwachs (2006), no começo do século $\mathrm{XX}$, já relacionava a memória com os grupos sociais de maneira sistemática, propondo a noção de memória coletiva, referindo-se às memórias de grupos que reconstroem o passado a partir de seus interesses presentes, concluindo que toda lembrança é sempre lembrança coletiva e rejeitando qualquer estudo que separasse o indivíduo das construções sociais.

No entanto, é interessante observar que o psicólogo russo Lev Vigotsky, nos anos trinta, também apresentou uma teoria da mente humana que apreende a dimensão social da memória, perspectiva, de certa forma, só recentemente incorporada pela psicologia, ou seja, pela chamada psicologia social.

Mas, aqui pretendemos nos apoiar nas discussões que consideram que, se não há história sem memória, e se as mesmas podem revelar realidades comuns, também revelam relações distinguíveis, conflitivas, uma vez que a primeira coloca em evidência problemas coletivos, públicos, manifestos em cada estágio alcançado por uma sociedade, e a segunda, 
pode ser apenas uma das apreensões desses momentos ou fonte de informação sobre eixos fundamentais para a produção historiográfica.

Como afirma Aróstegui (2004, p. 162), “a memória tem uma função importante com sustento das continuidades da experiência histórica, contudo: 'Memória e Historia [...] Não são necessariamente coincidentes nem ainda necessariamente convergentes em natureza, mas sua relação é contingente de forma inequívoca [...]. Destacando que o problema central a que devemos prestar a atenção é a maneira [...] como se estabelece a relação entre memória como representação permanente da experiência e historia como racionalização temporalizada, por assim dizer, de tal experiência [...].

Enfocando o problema desses pontos de vista, revisemos, de forma breve, os conceitos de geração desenvolvidos por Mannheim (1928), Ortega y Gasset, dentre outros, além dos conceitos de memória, particularmente de memória social, desenvolvido por Halbwachs (2006), para o entendimento do problema que nos interessa no momento: a reativação de memórias sociais, coletivas por grupos geracionais que conduzem às políticas de uma sociedade no presente.

Os estudos de Mannheim, desenvolvidos no século XX, e, em certa medida, os de Ortega y Gasset, elucidam o conceito de geração como um grupo social delimitado por sua posição de idade ou situação social particular, decorrente de seu pertencimento ao momento histórico determinado.

Poderíamos dizer que tanto Ortega y Gasset, quanto Mannheim conceituam geração como "um grupo de pessoas que, sendo contemporâneas e coetâneas, apresenta certa relação de coexistência, isso quer dizer, têm interesses comuns, inquietudes análogas ou circunstâncias parecidas" (ZARCO Y ORUETA apud GONZALEZ, 2007, p.8).

Em outras palavras, diríamos que o termo "geração" é carregado de múltiplos sentidos, mas, trataremos sua abordagem dentro do que há de mais consensual, ou seja, o sentido de que uma geração se constitui pelo fato de pertencerem a uma comunidade de pessoas nascidas no mesmo ano ou em anos próximos e, consequentemente, por participarem de certa posição de igualdade dentro do âmbito histórico e de certas formas de vivência e pensamento, sem desconsiderar-se sua "estratificação de vivências". (MANNHEIM, apud, MAGALHÃES, 2006).

A correlação entre "a contemporaneidade dos contemporâneos" já havia sido tratada por Dilthey (apud Magalhães, 1993, p.199), ao destacar que várias gerações vivem o mesmo tempo cronológico, mas, que há um tempo vivencial, qualitativo que é diferente um do outro. Contudo, Mannheim, se diferenciando de Dilthey, relaciona esse tempo vivencial e a sua base eminentemente social, não a um subjacente historicismo humano, mas como decorrente da relação dessas gerações com um dado tempo histórico, o qual possibilita vivências ante problemas ou situações históricas que atuam naquilo que ele denomina de “conexão geracional” (MAGALHÂES, 1999).

Mannheim (1928), envolvido pela discussão sobre a consciência social e o pertencimento a grupos concretos ou não, em decorrência de uma sociedade que revela o proletariado, mulheres e jovens em seus processos de autodefinição social, formula o fenômeno geracional como sendo um fenômeno social em reciprocidade com sua respectiva sociedade, recebendo influência do seu tempo histórico.

Em seu trabalho mais conhecido, O problema das gerações (1928), acaba delimitando o que é um grupo, quando extrai a noção de que há vínculos que os grupos não escolhem, mas, mesmo sem escolher, estão relacionados a um determinado grupo dados a sua existência vital em uma sociedade (MANNHEIM, 1999). E aqui nos parece que há uma proximidade com a noção de marcos coercitivos que produzem a memória coletiva, nos termos de Halbwachs (1925). 
Como mencionado acima, Mannheim (1928) destaca a ideia de conexão geracional em razão de uma posição de igualdade no âmbito histórico-social, pela proximidade do ano de nascimento, e que, portanto, a depender dos processos que afetam os indivíduos, eles acabam tendo determinadas formas de vivência e pensamento (MAGALHÃES, 1999).

Por sua vez, o conceito de memória em sua dimensão social, foi desenvolvido desde os finais do século XIX e início do século XX, principalmente com as contribuições de Bérgson (1896) e Freud (1904), ganhando vigor, de fato, quando Halbwachs (1925$1968^{2}$ ) conceitua memória social e coletiva e quando Bartlett (1932) discute a convenção da memória. Esses conceitos revigoram outros conceitos da sociologia, da psicologia, da história, da antropologia e de tantas outras ciências aplicadas.

Halbwachs (1968) em Os quadros sociais da memória, publicado em 1925, ressalta o vínculo da memória com seu caráter duradouro pela transmissão geracional, social: "toda a vida material e moral da sociedade das quais fazemos parte" (p.38) e que, a partir dos marcos sociais, ou seja, de um conjunto de pessoas, grupos, lugares, datas, constituímos nossa memória, que, em qualquer caso, depende de um desses quadros mais elementares para ser transmitida: a linguagem.

E, assim, há vários grupos componentes da sociedade, portanto, há tantas memórias quantos grupos existentes (HALBWACHS, 2006) e cada momento é um âmbito temporal que tem várias dimensões, que, por sua vez, são extraídas de forma comum ou distinta pelos diversos estratos geracionais que vivenciam o mesmo tempo (MANNHEIM, 1928).

Mas, diríamos que, se há muitas memórias coletivas conviventes com um dado tempo histórico, também há de se levar em conta que estas são historicamente construídas, e dificilmente poderemos apartá-las das relações de produção da vida material das relações de poder que lhes dão origem e sentido, dentro de uma dada conjuntura histórica e seu devir.

Essas memórias são balizadas por eventos históricos, mudanças sociais e preferências culturais que podem ter sido objeto de elaboração de alguns grupos, mas não necessariamente de todos os participantes de uma coletividade; porém, podem ser apropriadas por quase todos os integrantes de uma mesma geração, o que lhes confere uma identidade característica e única.

O estatuto de geração abrange a noção de que há grupos de contemporâneos e coetâneos que compartilham experiências e vivências comuns, mas o presente é o resultado da coetaneidade de uma geração ativa, que compartilha comportamentos, hábitos e vivências comuns de grupos, que seguem à medida que vão envelhecendo juntos (ARÓSTEGUI, 2004). Como existem vários grupos coetâneos, existem estratificações de vivências/experiências.

Não se pode perder de vista que essas experiências dos grupos coetâneos, apesar das singularidades de cada grupo, são frutos de um contexto histórico, de uma série de conjunturas (sincrônicas e diacrônicas) e características que definem os sujeitos sociais, sejam questões de trabalho, educação, sexo, religião, etc. (MAGALHÃES, 1999).

As gerações se renovam, afirma Aróstegui (2004), ao tratar mais especificadamente da relação entre história do presente e interação geracional. Para ele, existe um movimento dinâmico que aponta na mesma conjuntura uma realidade a qual anuncia que, na medida em que novos portadores de cultura emergem continuamente na sociedade, outras formas que coexistem permanecem, ou seja, o novo se imbrica com o velho, e, dessa forma, ocorre uma renovação geracional, constituída através de experiências vividas e apreendidas que apresentam uma síntese de uma realidade anterior com elementos novos, sendo e não, ao mesmo tempo, uma experiência inédita. 
Assim também considerou Thompson (1987), ao tratar mais especificadamente da conceituação de experiências comuns dos grupos sociais que, por sua vez, produzem memórias por meio da recuperação das experiências herdadas e partilhadas.

Aróstegui (2004), ao recorrer aos argumentos geracionais e ao campo de estudos da memória, ressalva o quanto o "[...] entrecruzamento destas memórias são absolutamente essenciais para a análise de fundo da memória histórica [...]" (ARÓSTEGUI, 2004, p.160).

Para o autor, "El movimiento generacional de las memorias, é um fenómeno da memoria histórica que não ocupa somente "a produção, convivencia e confrontação de varias memórias coetâneas, [...]", mas também "[...] senão que o tempo histórico vai conformando memórias sucessivas temporais, muitas vezes superpostas ou cortadas [...]", portanto, "[...] el movimiento generacional tem algo ou muito o que ver - ainda que em absoluto possa considerar-se a chave única - com a variação temporal dos conteúdos de memória (ARÓSTEGUI, 2007, p.8).

É nessa perspectiva que são importantes as observações apresentadas por Sá (2007a), quando este discute a memória social, ou seja, em seus aspectos teóricos mais abrangentes, a partir de uma perspectiva psicossocial, ao considerar que a mesma desempenha um caráter construtivo, de manter, atualizar e significar as experiências pessoais e de grupo, que aparecem tanto no campo do vivido, quanto no campo do apreendido e que possui variantes denominadas de memórias: coletivas, pessoais, comuns, geracionais, histórico-documentais e orais, práticas e públicas.

Por sua vez, há sempre de se perguntar quem, porque e em que sentido dadas memórias estão sendo usadas, pois não podemos esquecer de que as experiências e as lembranças vão se adaptando às convenções do grupo que as constitui. Em outras palavras:

Em relação com a memória coletiva, o aspecto geracional da mesma informa-a sobre o caráter comum dos conteúdo que são elaborados e selecionados de maneira conjunta por quem tem "expectativas" similares.Se elege o que é relevante e significativo em conexão com os interesses e a identidade dos membros do grupo. Por não haver um único grupo, são várias e distintas as memórias coletivas, as reinterpretações e reelaborações que entram em jugo e que geram tensões e conflitos (GONZALEZ, 2007, p.8).

Enfocamos as abordagens acima, visando destacar que o pensarmos sobre a apreensão da história pela memória, nos leva a observar que as continuidades que se operam pela transmissão social, conviventes diacrônica ou sincronicamente por meio da transmissão, portanto, pela memória coletiva de grupos que formam parte da memória social, pode ser uma, dentre outras que possibilita a discussão sobre o projeto de sociedade, educação, a escola, em voga.

Dentro dessa discussão, há uma forma de "pensar a História" considerando que há memórias geracionais (vividas ou herdadas) que entrecruzam o presente e continuam atuando por meio da transmissão geracional e que são as gerações vivas que dão sentido ao presente histórico. Certamente, supondo-se que o sentido dessa memória depende da situação vivida ou recebida, à medida que se prolonga. Portanto, a historicização da memória tem como operação cientifica precípua, considerar a relativização e a racionalização temporal do rememorado, ou seja, a seleção coletiva do recordado e do não lembrado, a partir da posição geracional daqueles que lembram, como das condições prévias para torná-la acessível a um discurso histórico. 
Isso significa que nunca devemos deixar de observar a operação de sua análise:

[...] a memória enquanto fonte histórica deve estar sujeita às mesmas condições que todas as demais, aos requisitos metodológicos aplicáveis a qualquer gênero de fonte histórica. Isso conduz ao mesmo gênero de operações que em todos os demais casos: identificação como fonte idônea, contrastação, contextualização temporal, relativização, objetivação e construção de um discurso metodologicamente fundamentado. Como o exemplo das fontes orais e as cautelas metodológicas a que se obrigam (ARÓSTEGUI, 2007, p. 165).

Diz, ainda, o autor que

[...] As memórias podem chegar ou não ao grau de uma verdadeira construção histórica, para que passe por um reelaboração em forma de discurso objetivado e provado, com uma certificação intersubjetiva, quer dizer, uma aceitação que nunca é perfeita e nem absoluta (ARÓSTEGUI, 2007, p. 165).

Esta pode ser uma das maneiras de a História da Educação acercar-se do presente, como síntese mais elaborada do passado, e de sua conjuntura política. É também uma maneira de perguntarmos quem são os grupos geracionais, sociais que têm operacionalizado as esferas de políticas e quais têm sido as readequações do passado ao presente educacional, de acordo com interesses, ideologias, usos e sentidos que estão direcionando concepções produtoras e reprodutoras de uma ideia de sociedade na longa, curta ou média duração.

Isso significa pensar a história da educação à luz dos processos políticos que estão operando o presente de uma sociedade que, historicamente, já não é a mesma de antes, mas que se aperfeiçoa, dadas as experiências em detrimento ou recomposição de umas sobre outras, a partir de quadros dominantes de uma sociedade.

Dessa forma, nos parece fundamental que a área de educação, cujo centro de discussão compreende os processos de transmissão social, se aproprie da análise sobre a ação da história sobre a memória e desta sobre a história, para pensar sobre as políticas, a educação, a escola no decorrer do tempo, e suas intervenções sobre o presente. Como por exemplo, certas memórias estão sendo usadas ou mobilizadas pelo Estado em seu estágio nacional, internacional, local, regional e seus grupos próximos e correlatos, e estão atuando na elaboração das políticas educacionais, nas políticas públicas, nas práxis pedagógica das escolas para referendar o presente histórico.

Sendo assim, os conceitos de memória social e memória coletiva geracional, sem desconsiderar outras abordagens, talvez permitam colocar em cena como a memória e a história de um passado longínquo ou recente, em sua continuidade e descontinuidade dialética, ainda possam ser integrantes do desenrolar histórico e educacional. Ademais, pode permitir que prestemos mais atenção ao presente, à luz das relações sociais sobreviventes, definindo novos territórios de análise para a apreensão dos processos políticos que estão conduzindo a educação no tempo da atualidade. 
Nessa perspectiva, vamos encontrar os ensaios de Magalhães (2008a; 2008b) que, a partir de uma abordagem intermediária, discute Memória Geracional e História da Educação, e destaca que os grupos geracionais que viveram ou tiveram acesso ou não a uma dada política educacional, dependeram forçosamente dessas condições para o acesso à escola, possivelmente constituíram uma memória sobre a escola, sobre essa sociedade, sobre o tipo de ação do Estado, entre outras.

Poderíamos dizer que esses grupos também compartilham uma experiência, um relato comum que integra o passado ao presente, formando uma memória, no presente, sobre a escola, sobre o Estado, integrando ao presente uma memória coletiva (dos grupos que vivenciaram diretamente essas experiências ou indiretamente, recebidas das gerações com as quais convivem). Esses grupos estão produzindo, possivelmente, representações sociais sobre as possibilidades de acesso à educação e sobre a escola, das políticas como direito ou assistência, por exemplo, mas também os elaboradores dessas políticas compartilham de visões que podem ser associadas às suas memórias geracionais.

Sendo assim, o conceito de gerações permite colocar em questão a imagem que uma sociedade tem do passado em sua continuidade e descontinuidade dialética, a partir da geração que protagoniza acontecimentos, fatos, experiências e/ou das gerações que, socializadas sob a tutela da memória dos eventos não vividos, mas que compuseram sua formação, a tal ponto de ainda ter uma grande representação sobre a memória social que integra o presente e interfere sobre o desenrolar histórico e educacional.

Desta forma, pretendemos evidenciar que, pensar a ação da história sobre a memória e esta sobre aquela, pode ser um dos caminhos para se pensar os usos pragmáticos, interesses de determinados grupos geracionais, políticos, partidários, que sem dúvida, por si só, não suplantam outras tantas dimensões presentes nessas relações sociais, mas podem colocar em cena o peso das memórias vividas ou transmitidas e adquiridas por grupos que estão comandando instâncias definidoras de uma sociedade e quais têm sido as percepções das experiências educacionais que estão colocando sob o crivo, o presente.

Sabemos que a categoria social e histórica da geração não elimina outras situações e dimensões presentes na estrutura das relações sociais que, por sua vez, são decisivas para a compreensão do funcionamento da sociedade (ARÓSTEGUI, 2004). Contudo, parecenos que, aqui, há uma categoria de análise central que precisa ainda ser revisitada, estudada, ao considerarmos as necessidades do presente, ou seja, é necessário que tenhamos recursos discursivos para apreender não só o sentido do estudo da memória, partindo da premissa de ação de um passado sobre o presente, mas, também, que tenhamos recursos para apreender quais são os processos de construção social da memória que estão se produzindo e se transmitindo às gerações, no presente.

\section{CONSIDERAÇÕES FINAIS}

No presente texto, tomamos como referências os estudos que apresentam distinções e similaridades para apreenderem a localização do tempo vivencial no tempo histórico. Diz respeito a uma relação que exprime igualmente uma relação coletiva no tempo, como também oferece ocasião para colocar em cena a história e a memória. Assim sendo, apresentamos, brevemente, as principais discussões que nos ofereceram diretrizes de análise sobre as noções de geração e memória e sobre as suas apropriações teóricoanalíticas, visando pensar o papel político que dados grupos geracionais podem jogar nos 
espaços e instituições públicas, na atualização de certas demandas e seus âmbitos ideológicos.

Desta maneira, quando propusemos esta sugestão analítica, pretendemos destacar que a relação entre memória e geração pode possibilitar a discussão sobre relações de poder e as representações do passado que melhor se acoplam aos interesses dominantes de uma época, a seus valores e interesses. Portanto, pensando assim:

Os modelos de uma política não são independentes da política cultural e dos valores.Suas relações são duplas. Primeiramente o modelo da política deve dar forma aos conceitos e aos valores mais gerais da ordem social.Segundo,deve estar em harmonia com as concepções dominantes de governo e com as formas de interação entre o Estado e as sociedade (JOBERT,1989,p.378).

No fundo, a questão central é a mesma: quais têm sido as memórias coletivas, geracionais produzidas, conservadas, elaboradas e transmitidas ao longo do tempo no seio de nossa sociedade, levando em consideração as políticas e as práticas educacionais em curso por aqueles que estão sendo os responsáveis pelo desempenho político de uma sociedade.

Desta perspectiva, poderíamos dizer que as discussões que relacionam memória e geração permitem a consideração de que aqueles grupos que estão na condução das esferas políticas de uma sociedade podem estar se apoiando em algum tipo de definição social da realidade de acordo com suas memórias geracionais, de acordo com determinadas visões de mundo, ancoradas nas necessidades e interesses que lhes sirvam para manter seus grupos no tempo e facultar a sua manutenção na definição dos rumos dominantes de uma sociedade.

\section{REFERÊNCIAS}

ARÓSTEGUI, Julio. Historia del presente e interacción generacional. In: La Historia Vivida. Sobre la historia del presente. Madrid: Alianza, 2004.

BARTLETT, Frederic Charles. Remembering: A study in experimental and social psychology. Cambridge, MA: Cambridge University Press, 1995. (Original publicado em 1932).

BERGSON, Henri. Matière et Mémoire - Essai sur la relation du corps a l'esprit. 54. ed. Paris: Presses Universitaires de France, 1953. (Publicação original em 1896).

FREUD, Sigmund. Recuerdos infantiles y encubridores. Psicopatologia de la vida cotidiana. In: Obras completas de Sigmund Freud. Buenos Aires: Santiago Rueda Editor, v. 1, 1953, p. 57-64. (Publicação original 1904).

GONZÁLEZ, Magdalena. Apuntes para un método de análisis mnemónico intergeneracional sobre la Guerra Civil. In: Hispania Nova: Revista de Historia 
Contemporánea. $\quad$ n6, $2006 . \quad$ Disponível em: <http://hispanianova.rediris.es/6/dossier/6d014.pdf >. Acesso em: maio de 2010.

HALBWACHS, Maurice. A memória coletiva. São Paulo: Centauro, 2006.

La mémorire collective. Paris: PUF, 1968.

JOBERT,D. The normative frameworks of public policy,in Political Studies,n XXXVII,1989.

MAGALHÃES, Lívia Diana Rocha. A trajetória das gerações brasileiras nascidas entre 1926 e 1975: um perfil sociodemográfico. Tese (Doutorado em Educação) - Universidade Estadual de Campinas. Campinas/SP: UNICAMP, 1999.

Políticas educacionais e trajetórias geracionais: primeiros relatos da pesquisa em Vitória da Conquista-Ba. In: Anais do VI Colóquio do Museu Pedagógico. Vitória da Conquista, 2006.

Educação, História e Memória: uma aproximação do estudo geracional. In: Revista HISTEDBR on line. Campinas: UNICAMP, 2007. nº 28.

Magalhães, L.D.R (2008a). Política Educacional: uma abordagem sócio-histórica. ETD. Educação Temática Digital, v. 16, p. 61-65. Disponível no link: http://www.uepg.br/propesp/publicatio/hum/2008_1/artigo-7-Livia-61-65.pdf

(2008b). Educação, História e Memória: uma aproximação do estudo geracional. Revista HISTEDBR On-line. Campinas: UNICAMP/FE. v. 30, p. 99-105. Disponível no link: http://www.histedbr.fae.unicamp.br/revista/edicoes/28/art07_28.pdf

MANNHEIM, Karl. El problema de las geraciones. In: Revista de Investigación Sociológica. Madrid. 1993, n.62 (publicado originalmente em 1928).

SÁ, Celso Pereira de; CASTRO, Paula. Memórias do descobrimento do Brasil. Rio de Janeiro: Museu da República, 2005.

Sobre o campo de estudo da memória social: uma perspectiva psicossocial.In:

Revista Psicologia Reflexão e Crítica. Rio Grande do Sul: UFRGS, 2007a. V. 20.

Disponível no site: www.scielo.br/prc.

Sobre a psicologia social no Brasil, entre memórias históricas e pessoais. In:

Psicologia \& Sociedade. Florianópolis/SC: Associação Brasileira de Psicologia Social, $2007 b$.

THOMPSON, Edward. P. A formação da classe operária inglesa. A árvore da liberdade. Rio de Janeiro: Paz e Terra, 1987. Vol I. 


\section{Notas:}

${ }^{1}$ Mestre em Educação pela Universidade de São Carlos - UFSCar; Doutora em Educação pela Universidade Estadual de Campinas - UNICAMP; com Pós-Doutorado em Psicologia Social pela Universidade Estadual do Rio de Janeiro - UERJ. Professora Plena do Departamento de Filosofia e Ciências Humanas - DFCH, da Universidade Estadual do Sudoeste da Bahia - UESB. Coordenadora Geral do Museu Pedagógico da UESB; Professora e Coordenadora do Programa de Pós-Graduação Stricto Sensu em Memória: Linguagem e Sociedade (UESB). Membro do HISTEDBR e do HISTED-BS. E-mail: 1rochamagalhaes@ gmail.com

${ }^{2}$ Estamos nos referindo o período que compreende a primeira publicação e a obra póstuma Memória Coletiva.

É nossa a tradução do espanhol para o português das citações relativas às publicações de ARÓSTEGUI ( 2004 ) e de GONZALÉZ (2010).

Recebido em abril-2014

Aprovado em maio-2014 